\title{
Nano/micro-mechanical and tribological characterization of Ar, C, N, and Ne ion-implanted Si
}

\author{
Zhi-Hui Xu \\ Department of Mechanical Engineering, University of South Carolina, \\ Columbia, South Carolina 29208 \\ Young-Bae Park \\ Thomas J. Watson Laboratory of Applied Physics, California Institute of Technology, \\ Pasadena, California 91125 \\ Xiaodong $\mathrm{Li}^{\mathrm{a}}$ \\ Department of Mechanical Engineering, University of South Carolina, \\ Columbia, South Carolina 29208
}

(Received 16 May 2009; accepted 23 September 2009)

\begin{abstract}
Ion implantation has been widely used to improve the mechanical and tribological properties of single crystalline silicon, an essential material for the semiconductor industry. In this study, the effects of four different ion implantations, $\mathrm{Ar}, \mathrm{C}, \mathrm{N}$, and $\mathrm{Ne}$ ions, on the mechanical and tribological properties of single crystal Si were investigated at both the nanoscale and the microscale. Nanoindentation and microindentation were used to measure the mechanical properties and fracture toughness of ion-implanted $\mathrm{Si}$. Nano and micro scratch and wear tests were performed to study the tribological behaviors of different ion-implanted Si. The relationship between the mechanical properties and tribological behavior and the damage mechanism of scratch and wear were also discussed.
\end{abstract}

\section{INTRODUCTION}

As one of the most important materials in semiconductor industry, single crystalline silicon has been widely used in fabrication of various miniature components, such as, micro-/nano-electromechanical systems (MEMS/NEMS). Due to the brittle nature of $\mathrm{Si}$, the failure of MEMS/NEMS devices often occurs during applications because of the large friction and wear. ${ }^{1}$ Various surface modification techniques have been applied to create a surface layer to improve the mechanical and tribological properties of Si. Among these techniques, ion implantation has proved to be one of the most effective ways to modify the tribological properties of $\mathrm{Si}$ with a full control of the composition of the implanted layer and a strong adhesion between the implanted layer and the substrate. ${ }^{2}$ Different ions such as $\mathrm{Ar}^{3,4} \mathrm{C},{ }^{5,6} \mathrm{H},{ }^{7,8} \mathrm{~N},{ }^{5,6,9} \mathrm{Ne},{ }^{10,11} \mathrm{Cr}^{12} \mathrm{P},{ }^{13}$ and $\mathrm{O}^{7}$ have been used to implant $\mathrm{Si}$ to improve either the mechanical and/or tribological properties or other electrophysical properties. Although much work has focused on the effect of individual ion implantation on the mechanical and tribological behavior of implanted $\mathrm{Si}$, direct comparison of mechanical and tribological behavior of different ion-implanted $\mathrm{Si}$ is still lacking and research on the difference of damage mechanisms among different ion

\footnotetext{
a) Address all correspondence to this author.

e-mail: lixiao@engr.sc.edu

DOI: 10.1557/JMR.2010.0117
}

implantations during scratch and wear is still scant. This information is essential to fully understand the role of ion implantation in the improvement of mechanical and tribological behaviors of $\mathrm{Si}$ and to produce high quality products.

In the present paper, we have focused our investigation on the effects of four common ion implantations, $\mathrm{Ar}, \mathrm{C}, \mathrm{N}$, and $\mathrm{Ne}$ ions, on the mechanical and tribological properties of single crystal $\mathrm{Si}$ at both the nanoscale and the microscale as well as the macro scale. Nanoindentation and microindentation have been used to measure mechanical properties and fracture toughness of ion-implanted $\mathrm{Si}$. Nano/micro scratch and wear tests have been performed to investigate the tribological behaviors of different ion implanted Si. The damage mechanisms of scratch and wear have also been discussed.

\section{EXPERIMENTAL}

Samples of single crystal silicon with an orientation of (100) were implanted with ions of Ar, C, N, and Ne. All ions were implanted with a calibrated ion dose from the stopping and range of ions in matter (SRIM) $\operatorname{code}^{14}$ and the ion projected range for all ions were adjusted by different ion energy to obtain the same depth of ions in the Si substrate near $200 \mathrm{~nm}$. Detailed ion implantation condition and simulation results are shown in Table I. Total ion dose and the number of displaced atoms (Frenkel pairs) were obtained from Monte Carlo simulation and Kinchin 
TABLE I. Ion implantation condition and simulation result for collision-induced defects for each ion.

\begin{tabular}{lcccc}
\hline \hline Ion & $\begin{array}{c}\text { Ion energy } \\
(\mathrm{keV})\end{array}$ & $\begin{array}{c}\text { Ion projected } \\
\text { region (Dp) }\end{array}$ & $\begin{array}{c}\text { Dose } \\
\left.\text { (ion/cm }{ }^{2}\right)\end{array}$ & $\begin{array}{c}\text { Collision damage } \\
\text { (\#/Å-ion) } \\
\text { from K-P theory }\end{array}$ \\
\hline $\mathrm{Ar}$ & 200 & $206.4 \mathrm{~nm}$ & $2.2 \times 10^{15}$ & 0.92 \\
$\mathrm{C}$ & 70 & $205.2 \mathrm{~nm}$ & $1.0 \times 10^{16}$ & 0.20 \\
$\mathrm{~N}$ & 80 & $199.4 \mathrm{~nm}$ & $8.0 \times 10^{15}$ & 0.25 \\
$\mathrm{Ne}$ & 100 & $205.5 \mathrm{~nm}$ & $5.0 \times 10^{15}$ & 0.40 \\
\hline \hline
\end{tabular}

and Pease $(\mathrm{K}-\mathrm{P})^{15}$ in the SRIM code. The ion dose is $2.2 \times 10^{15} \mathrm{ion} / \mathrm{cm}^{2}$ for Ar, $1.0 \times 10^{16} \mathrm{ion} / \mathrm{cm}^{2}$ for $\mathrm{C}$, $8.0 \times 10^{15} \mathrm{ion} / \mathrm{cm}^{2}$ for $\mathrm{N}$, and $5.0 \times 10^{15} \mathrm{ion} / \mathrm{cm}^{2}$ for $\mathrm{Ne}$, with the same beam current. All implantations were performed at room temperature.

In order to determine whether there is any formation of silicon carbide and silicon nitride during $\mathrm{C}$ and $\mathrm{N}$ ion implantation, X-ray photoelectron spectroscopy (XPS) measurements were conducted on the Kratos AXIS Ultra DLD XPS system (Manchester, UK) equipped with a monochromatic Al $\mathrm{K} \alpha$ source. The monochromatic Al $\mathrm{K} \alpha$ source was operated at $15 \mathrm{keV}$ and $150 \mathrm{~W}$. Detailed scans for $\mathrm{C} 1 s, \mathrm{~N} 1 s$, and $\mathrm{Si} 2 p$ spectra were performed with a pass energy of $40 \mathrm{eV}$.

Nanomechanical and tribological characterizations were performed on all ion implanted samples and a virgin Si control sample. Nanoindentation was carried out to measure the mechanical properties of the implanted surface layers using Triboscope (Hysitron Inc., Minneapolis, $\mathrm{MN})$. A well calibrated pyramidal diamond Berkovich indenter was used for a nanoindentation test. A peak indentation load of $250 \mu \mathrm{N}$ was applied to the indenter with a constant loading rate of $50 \mu \mathrm{N} / \mathrm{s}$, held for $5 \mathrm{~s}$, and then totally released with an unloading rate of $50 \mu \mathrm{N} / \mathrm{s}$. At least eight indents were made on each sample. Considering that the ion implanted surface layers are about $200 \mathrm{~nm}$, to eliminate any substrate effects, ${ }^{16,17}$ the peak indentation load was so selected that the average maximum penetration depth into the surface layer was about $22.25 \mathrm{~nm}$ with an average contact depth of about $13.80 \mathrm{~nm}$. The hardness and elastic modulus were determined from the unloading curve of indentation using the Oliver and Pharr method. ${ }^{18}$ A Poisson's ratio of 0.27 and a correction factor of $1.225^{19}$ were used for the elastic modulus calculation.

A microindentation test was performed to determine the fracture toughness of ion implanted samples using a Beuhler Micromet-1 microhardness tester (Buehler Ltd., Lake Bluff, IL). A diamond Vickers indenter was used for the test. A peak indentation force of $0.5 \mathrm{~N}$ was applied over $30 \mathrm{~s}$. The indentation force was so chosen that it was large enough to create radial cracks at the corners of Vickers indent for all the tested samples with no spallation of materials. The fracture toughness $\mathrm{K}_{\mathrm{IC}}$ was calculated using the following equation ${ }^{20}$ :

$$
K_{\mathrm{IC}}=\alpha\left(\frac{E}{H}\right)^{1 / 2}\left(\frac{P}{c^{3 / 2}}\right),
$$

where $\alpha$ is an empirical constant depending on the geometry of the indenter and equal to 0.016 for Vickers indenter, ${ }^{20} E$ is elastic modulus, $H$ is hardness, $P$ is the peak indentation force, and $c$ is the crack length. Both $E$ and $H$ were obtained from nanoindentation data. The crack length was measured from the center of the indent to the end of crack using optical microscope. At least six indents were made on each sample to determine the fracture toughness.

The surface roughness of each sample was measured by $1 \times 1 \mu \mathrm{m}$ scan area using a silicon tip with a nominal tip radius less than $10 \mathrm{~nm}$ in tapping mode atomic force microscopy (AFM, Dimension 3100, Veeco Metrology Group, NY).

Tribological characterizations of the ion implanted samples were performed at both nanoscale and microscale, with the former representing a normal service condition while the latter imitating a rather harsh condition. A nanoscratch test was done on all samples using a nanoindentation probe with a pyramidal diamond attached to a stainless steel cantilever. Five scratches with a length of $3 \mu \mathrm{m}$ were done on each sample with different normal scratch forces of $5.75,6.90,8.05,9.20$, and $10.35 \mu \mathrm{N}$. After scratching, the same tip was used to scan the scratched surfaces to obtain the topographical images. The average scratch depth under each normal scratch force was measured from the central part of each scratch and used to evaluate the resistance of the surface damage at the nanoscale.

Microscratch as well as friction and wear tests were performed using a CETR microtribometer (CETR Inc., Campbell, CA). In the microscratch test, a conical diamond indenter with a tip radius of $1.5 \mu \mathrm{m}$ and an included angle of $60^{\circ}$ was drawn on the sample surface over a scratch distance of $4 \mathrm{~mm}$ with a ramping load from $5.4 \mathrm{mN}$ to $45.3 \mathrm{mN}$. An acoustic emission (AE) sensor was attached to the scratched sample to monitor the variation of $\mathrm{AE}$ signal during scratching. A critical load corresponding to a burst of AE signal was used to evaluate the local failure at microscale. The coefficient of friction, friction force, and normal load were also detected in situ during scratching. The friction and wear tests were carried out against a WC ball with a radius of $2 \mathrm{~mm}$ and a surface finish of about $2 \mathrm{~nm}$ root-mean-square (RMS) in reciprocating mode. Two different normal loads of $0.05 \mathrm{~N}$ and $1.5 \mathrm{~N}$ were used for the friction and wear tests with a total sliding distance of $240 \mathrm{~mm}$. Other test conditions were as follows: stroke length $6 \mathrm{~mm}$, frequency $0.033 \mathrm{~Hz}$, average linear speed $0.4 \mathrm{~mm} \mathrm{~s}^{-1}$, temperature $23 \pm 1{ }^{\circ} \mathrm{C}$, and relative humidity $45 \pm 5 \%$. Scratch and wear tracks were observed using a PME3 optical microscope (Olympus, Japan) with a XCD-SX900 digital interface (Sony, Japan). All scratch and wear tests were repeated at least 3 times. 


\section{RESULTS AND DISCUSSION}

\section{A. Elastic modulus and hardness}

Figure 1 shows the elastic moduli, hardnesses, and typical nanoindentation curves of control sample and ion implanted silicon samples. The typical nanoindentation load-penetration depth curves of the control sample and different ion implanted samples are shown in Fig. 1(a). Compared to the nanoindentation curve of the control sample, all the ion implanted samples have a shallower penetration depth except the Ar implanted one, which is a result of different surface modifications by ion implantations. It is well known that $\mathrm{Si}$ is an anisotropic material and the value of elastic modulus depends highly on the crystalline orientation. ${ }^{21}$ The elastic modulus of the control sample measured by nanoindentation is $123.65 \pm$ $3.49 \mathrm{GPa}$, which is in accordance with the one determined by optical measurement for (100) Si wafer (125.6 $\pm 1.4 \mathrm{GPa}){ }^{21}$ The measured hardness for the control

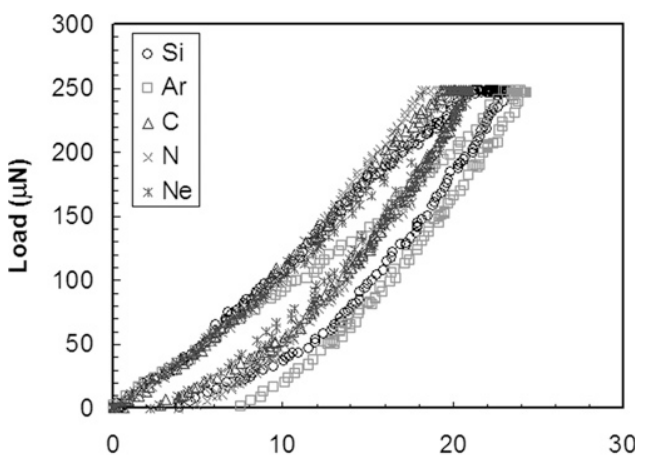

(a)

Penetration Depth (nm)
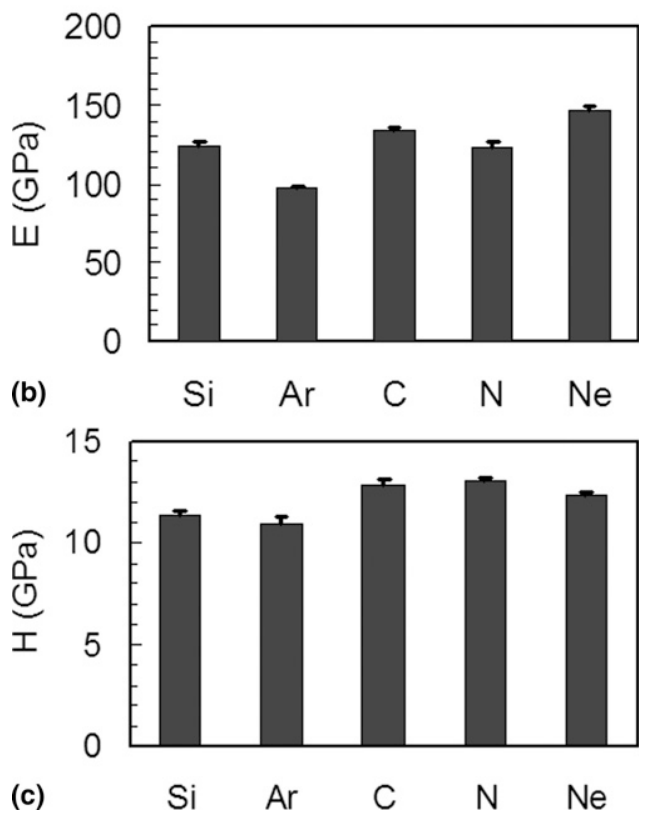

FIG. 1. (a) Typical nanoindentation curves, (b) elastic modulus, and (c) hardness for ion implanted samples and control sample. Error bars denote the standard errors. sample is $11.36 \pm 0.19 \mathrm{GPa}$, which is similar to the values in literature. ${ }^{4,22}$ Compared to virgin $\mathrm{Si}$, all the ion implantations enhance the mechanical properties, namely elastic modulus and hardness, except Ar implantation [Figs. 1(b) and 1(c)].

The difference in mechanical properties for different ion-implantations may be related to the difference in the interaction of the individual ion with $\mathrm{Si}$ substrate. For $\mathrm{C}$ and $\mathrm{N}$ implantations, the increase of mechanical properties, especially the hardness, is usually attributed to the formation of strong compounds like $\mathrm{SiC}$ and $\mathrm{Si}_{3} \mathrm{~N}_{4}$ during ion implantation. ${ }^{6}$ To determine whether there are silicon carbide and silicon nitride formations during $\mathrm{C}$ and $\mathrm{N}$ ion implantations, XPS analysis was performed on $\mathrm{C}$ and $\mathrm{N}$ ion implanted surfaces. Figure 2 shows the XPS spectra of C1s and Si2p for C ion implanted surface [Fig. 2(a)] and N1s and Si2p for N ion implanted surface. As shown in Fig. 2(a), all three peaks for $\mathrm{C} 1 \mathrm{~s}$ are the ones for adventitious carbons with $\mathrm{C}-\mathrm{C}$ bond $(284.8 \mathrm{eV}),{ }^{23} \mathrm{C}-\mathrm{O}(286.5 \mathrm{eV})$, and $\mathrm{C}=\mathrm{O}(289.5 \mathrm{eV}),{ }^{24}$ respectively. The two peaks for $\mathrm{Si} 2 \mathrm{p}$ are $\mathrm{Si}-\mathrm{Si}(99.5 \mathrm{eV})$ and $\mathrm{Si}-\mathrm{N}(102.1 \mathrm{eV})$ bonds. ${ }^{25}$ This indicates that there is no $\mathrm{Si}-\mathrm{C}$ bond formed during $\mathrm{C}$ ion implantation in this study since neither the peak for $\mathrm{C} 1 \mathrm{~s}-\mathrm{Si}(283.3 \mathrm{eV})$ nor the peak for Si2p-C (100.5 eV) occurs. ${ }^{26}$ Figure 2(b) shows the XPS analysis of $\mathrm{N}$ ion implanted surface. As can be seen, the two peaks for N1s are N-Si $(397.5 \mathrm{eV})^{27}$ and $\mathrm{N}-\mathrm{C}(400.3 \mathrm{eV})^{25}$ bonds while the two peaks for $\mathrm{Si} 2 \mathrm{p}$ are $\mathrm{Si}-\mathrm{Si}(99.5 \mathrm{eV})$ and $\mathrm{Si}-\mathrm{N}(102.1 \mathrm{eV})$ bonds. $^{25}$ This may confirm the formation of $\mathrm{Si}-\mathrm{N}$ bond during $\mathrm{N}$ ion implantation. For Ar implantation, the decrease of elastic modulus and hardness is due to the amorphization on the $\mathrm{Si}$ surface caused by the accumulation of radiation damage, which creates a layer of amorphous $\mathrm{Si}$ during the Ar implantation. ${ }^{3,4}$ Amorphous Si often has lower mechanical properties than crystal $\mathrm{Si}^{3,4,22}$ For $\mathrm{Ne}$ implantation, an increase of both elastic modulus and hardness is also observed. The retained $\mathrm{Ne}$ in $\mathrm{Si}^{11}$ might cause the distortion of $\mathrm{Si}$ structure and contribute to the difference in mechanical properties. However, further research is needed to clarify the mechanisms.

\section{B. Fracture toughness}

Figure 3 shows the optical images of typical Vickers indents with radial cracks and the fracture toughness for the control sample and all ion implanted samples. As shown in Figs. 3(a)-3(e), the size of Vickers indents and the length of radial cracks for the control sample and ion planted samples are similar. In fact, the Vickers indentation is rather deep compared to the ion implanted layer (about $200 \mathrm{~nm}$ ) and therefore the fracture toughness is dominated by the Si substrate underneath the ion implanted layer. Thus, the thin ion implanted layers have little contribution to the improvement of fracture toughness 

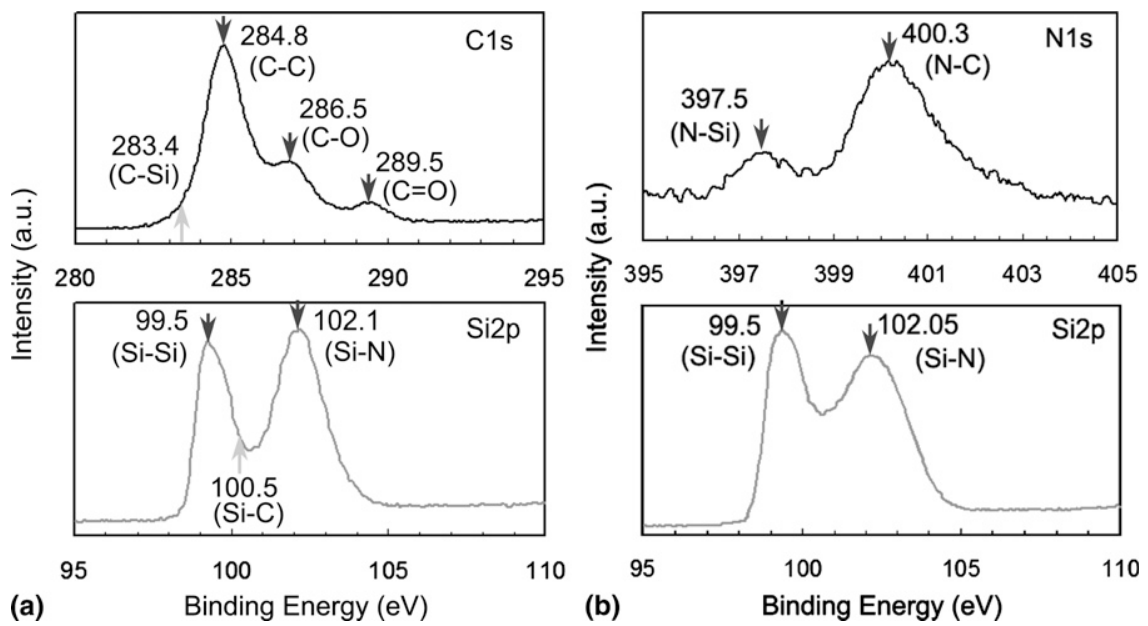

FIG. 2. XPS analysis of $\mathrm{C}$ and $\mathrm{N}$ ion implanted surfaces. (a) $\mathrm{C} 1 s$ and $\mathrm{Si} 2 p$ peaks of $\mathrm{C}$ ion implanted surface. (b) $\mathrm{N} 1 s$ and $\mathrm{Si} 2 p$ peaks of $\mathrm{N}$ ion implanted surface.

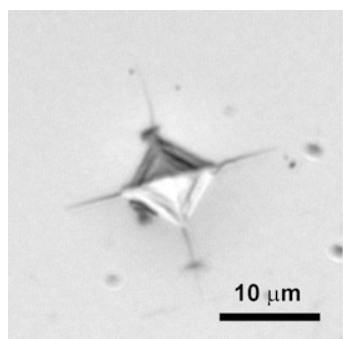

(a)

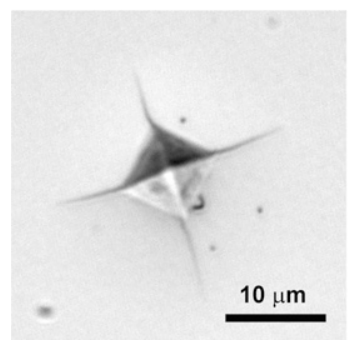

(d)

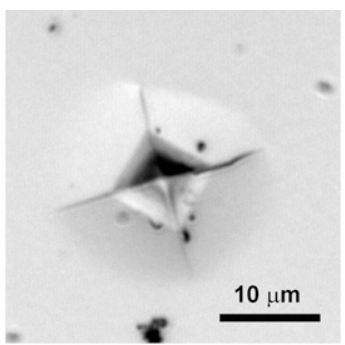

(b)

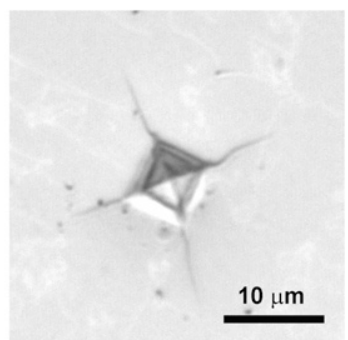

(e)

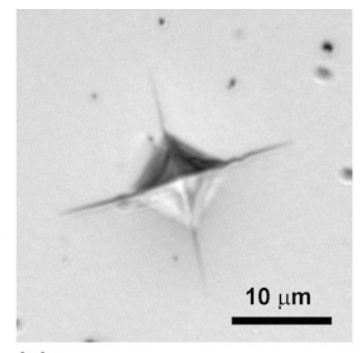

(c)

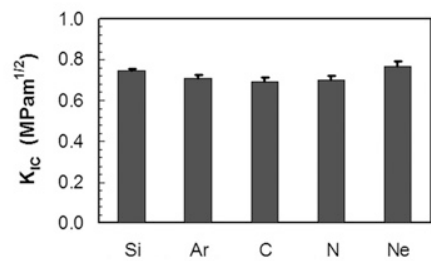

(f)

FIG. 3. Typical Vickers indents with radial cracks at the corner and fracture toughness for all samples. (a) Si, (b) Ar, (c) C, (d) N, (e) Ne, and (f) fracture toughness. Error bars denote the standard errors.

of Si wafer. This leads to very similar fracture toughness for all ion implanted samples and the control sample as shown in Fig. 3(f).

\section{Surface roughness and nanoscratch resistance}

Figure 4 shows the surface roughness measured by AFM. Compared to the control sample [Fig. 4(a)], the feature on the surfaces of different ion implanted samples [Figs. 4(b)-4(e)] are clearly finer. The RMS value of the control sample is $0.35 \mathrm{~nm}$ [Table II and Fig. 4(f)], which is similar to the RMS values $0.1-0.3 \mathrm{~nm}$ for virgin $\mathrm{Si}$ (100) available in literature. ${ }^{28-31}$ It has been observed that low fluences of different ion implantations have no significant/ noticeable effect on the surface roughness. ${ }^{28-30,32}$ On the other hand, high fluences of ion implantations have been found to increase the surface roughness ${ }^{29,31}$ due to the severe damage caused by ion irradiation. As shown in Fig. 4(f), for the fluences of ion implantations used in this study, the surfaces of ion implanted samples are either smoother than (for Ar, C, and $\mathrm{Ne}$ ) or similar to (for N) that of the control sample. Similar observation has also been reported for self-implanted $\mathrm{Si}(100)$ that surface roughness is reduced from $0.3 \mathrm{~nm}$ before implantation to $0.2 \mathrm{~nm}$ after implantation. ${ }^{30}$

Figure 5 shows the morphology of nanoscratches and the scratch depth of different samples with normal scratch forces from 5.75 to $10.35 \mu \mathrm{N}$. As shown in Figs. 5(a)-5(e), five scratches were made on each sample with increasing 

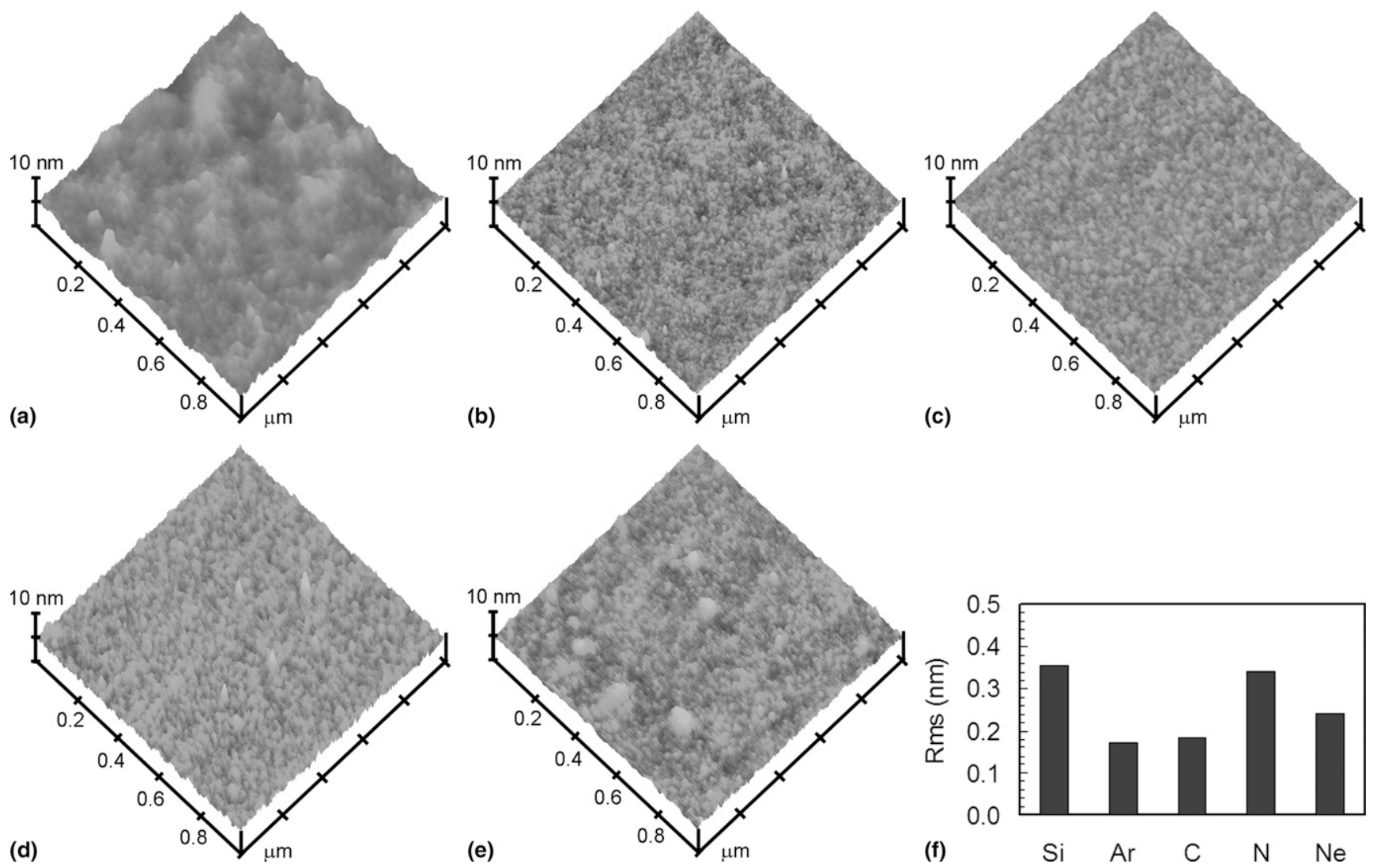

FIG. 4. AFM images of surface morphologies and surface roughness for all samples. (a) Si, (b) Ar, (c) C, (d) N, (e) Ne, and (f) surface roughness.

TABLE II. Surface roughness of sample surface, $H / E$ ratio, critical load of scratch damage, maximum AE signal, friction coefficients of first stroke, and last stroke of wear with normal load of 0.05 and $1.5 \mathrm{~N}$.

\begin{tabular}{|c|c|c|c|c|c|c|c|c|}
\hline \multirow[b]{2}{*}{ Material } & \multirow[b]{2}{*}{ RMS (nm) } & \multirow[b]{2}{*}{$H / E$} & \multirow[b]{2}{*}{ Critical load (mN) } & \multirow[b]{2}{*}{ Max. AE (V) } & \multicolumn{2}{|c|}{$0.05 \mathrm{~N}$} & \multicolumn{2}{|c|}{$1.5 \mathrm{~N}$} \\
\hline & & & & & $\mathrm{COF}, \mathrm{FS}$ & COF, LS & $\mathrm{COF}, \mathrm{FS}$ & COF, LS \\
\hline $\mathrm{Si}$ & 0.35 & 0.09 & $11.38 \pm 0.58$ & 0.08 & $0.150 \pm 0.012$ & $0.139 \pm 0.007$ & $0.156 \pm 0.010$ & $0.341 \pm 0.004$ \\
\hline $\mathrm{Ar}$ & 0.17 & 0.11 & $9.65 \pm 0.65$ & 4.70 & $0.181 \pm 0.011$ & $0.167 \pm 0.003$ & $0.254 \pm 0.017$ & $0.632 \pm 0.003$ \\
\hline $\mathrm{C}$ & 0.18 & 0.10 & $13.36 \pm 0.66$ & 2.21 & $0.165 \pm 0.011$ & $0.224 \pm 0.009$ & $0.169 \pm 0.006$ & $0.614 \pm 0.008$ \\
\hline $\mathrm{N}$ & 0.34 & 0.11 & $14.35 \pm 0.31$ & 2.53 & $0.154 \pm 0.008$ & $0.143 \pm 0.004$ & $0.210 \pm 0.012$ & $0.518 \pm 0.006$ \\
\hline $\mathrm{Ne}$ & 0.24 & 0.08 & $16.00 \pm 0.26$ & 1.65 & $0.090 \pm 0.008$ & $0.221 \pm 0.012$ & $0.224 \pm 0.013$ & $0.490 \pm 0.014$ \\
\hline
\end{tabular}

Note: Si denotes the virgin control sample. Ar, C, N, and Ne denote the ion implanted samples. FS denotes the first stroke of wear and LS the last stroke.

normal forces $5.75,6.90,8.05,9.20,10.25 \mu \mathrm{N}$ from right to left, respectively. Clearly, nanoscratching of the control sample and the ion implanted samples is dominated by plowing and no debris is observed along the scratches. In order to determine average scratch depths under different normal forces, an average surface profile of the central part of the scratched region is constructed as shown in Fig. 5(f). A typical analyzed area is indicated by the inset in Fig. 5(f). Considering the surface roughness, the scratch depth for each individual normal force is determined by averaging the depths measured from both sides of the individual scratch. The relationship between the normal scratch force and the scratch depth for different materials is shown in Fig. 5(g). As expected, the scratch depth basically increases with the increasing normal scratch force. Overall, the ion implanted samples have a shallower scratch depth at a given normal scratch force than the control sample, though this is not the case for the $\mathrm{Ne}$ implanted sample. This may be explained by the ratio of hardness $(H)$ and elastic modulus $(E)$, which is a key factor to define the scratch and wear resistance of materials. ${ }^{33,34}$ The $H / E$ ratio of the control sample and different ion implanted samples are listed in Table II. As can be seen, all of the ion implanted samples have a higher $H / E$ ratio than the control sample except for the $\mathrm{Ne}$ implanted sample. Therefore, Ar, C, and $\mathrm{N}$ implanted samples have higher scratch resistance and thus shallower scratch depth than the control sample. The Ne implanted sample has 


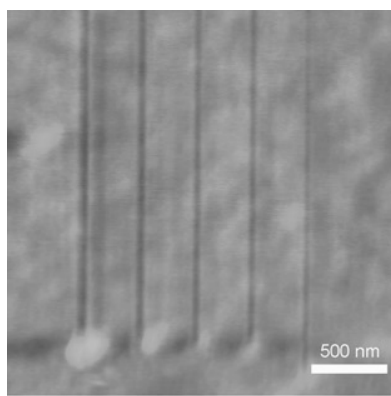

(a)

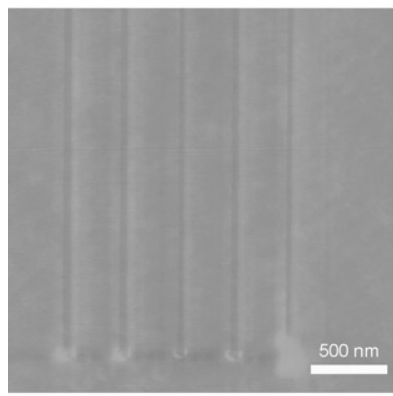

(c)

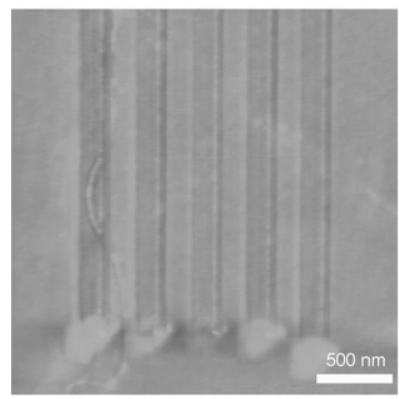

(e)

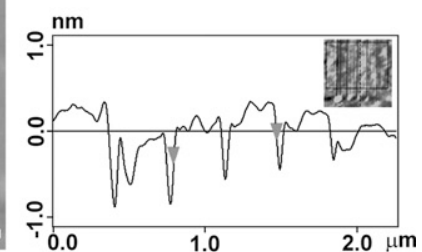

(f)

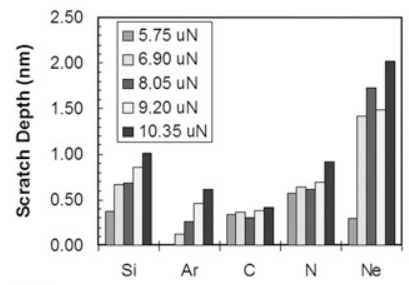

(g)

FIG. 5. AFM images of morphologies of nanoscratches and scratch depths at different normal scratch forces for all samples. (a) Si, (b) Ar, (c) C, (d) N, (e) Ne, (f) typical average profile of scratches, and (g) scratch depths at different normal scratch forces.

lower scratch resistance and thus a deeper scratch depth than the control sample.

\section{Microscratch resistance}

Figure 6 shows the coefficient of friction and AE signal as a function of the normal scratch force and the optical images of three regions over scratches: at the beginning of the scratch (Column A), around the point of initiation of damage, where a burst of $\mathrm{AE}$ occurs (Column B), and toward the end of the scratch (Column C) for all samples.
As can be seen, the coefficient of friction for all samples increases steadily with the increase of the normal scratch force at the beginning of the scratch because of the increased plowing of the sample by the tip. At that point, an abrupt increase in coefficient of friction occurs with further increase of the normal scratch force, indicating catastrophic failure and significant plowing of the tip into the sample. The initial burst in coefficient of friction may be used to define the critical load of scratch beyond which failure occurs. ${ }^{35,36}$ The AE signal for all samples is weak and almost constant with the increasing scratch normal force at the beginning of the scratch. With the further increase of the scratch normal force, the $\mathrm{AE}$ signal becomes stronger and bursts occur for all the samples. Compared to the AE signal of the control sample with a magnitude of $0.08 \mathrm{~V}$, all ion implanted samples exhibit much stronger $\mathrm{AE}$ signal with a magnitude from $1.65 \mathrm{~V}$ (Ne) to $4.70 \mathrm{~V}$ (Ar) (see Table II), which might be attributed to the damage between the interface of the implanted layer and the substrate.

It has been shown that the AE signal has a high sensitivity to local failure and is a good experimental parameter for monitoring the onset of damage during scratching and wear of hard coatings. ${ }^{37-39}$ Recent research shows that the AE signal can give a more precise determination of the initiation of local failure compared to the coefficient of friction. ${ }^{39}$ A burst of AE signal is often observed when a local failure happens, which can be used to detect the critical load for scratch damage. A typical AE signal as a function of normal load at the initial stage of microscratch and the critical loads for all materials are shown in Fig. 7. As shown in Fig. 7(a), the AE signal is constant and close to zero when the normal load is smaller than the critical load (denoted by the arrow). At the critical load, a burst of AE signal occurs, which indicates that local damage happens during the microscratch. When the normal load is larger than the critical load, continuous bursts of AE signal occur with larger magnitude, which shows more severe local damage at the higher normal load. The critical loads for different materials determined from the $\mathrm{AE}$ signal are shown in Fig. 7(b). As can be seen, the critical loads for all materials are comparable; however, the values for $\mathrm{C}, \mathrm{N}$, and $\mathrm{Ne}$ implanted samples are higher than the control sample, while that for Ar implanted sample is smaller.

The tribological behaviors of ion-implanted $\mathrm{Si}$ are different at the nanoscale and the microscale. For a nanoscratch, which may represent a normal service condition for MEMS and NEMS, the tip penetration is shallow and deformation is within the ion implanted layers. The tribological behaviors of the ion implanted layers are dominated by plowing, that is, the plastic deformation of materials. However, for a microscratch that may correspond to a harsh service condition, the tip penetration is much deeper and tribological behaviors are mainly dominated 
$\mathrm{AE}$ and $\mathrm{COF}$
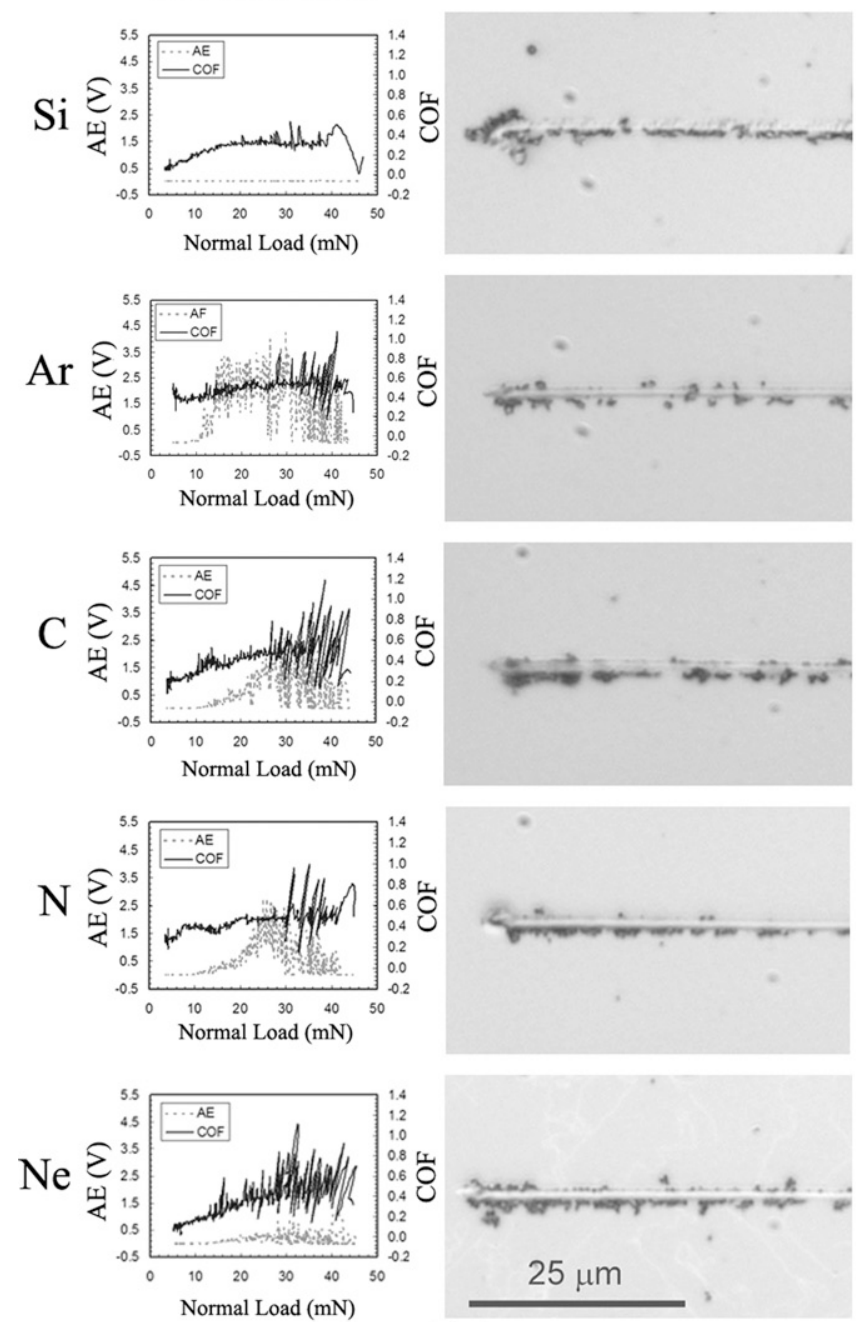

A
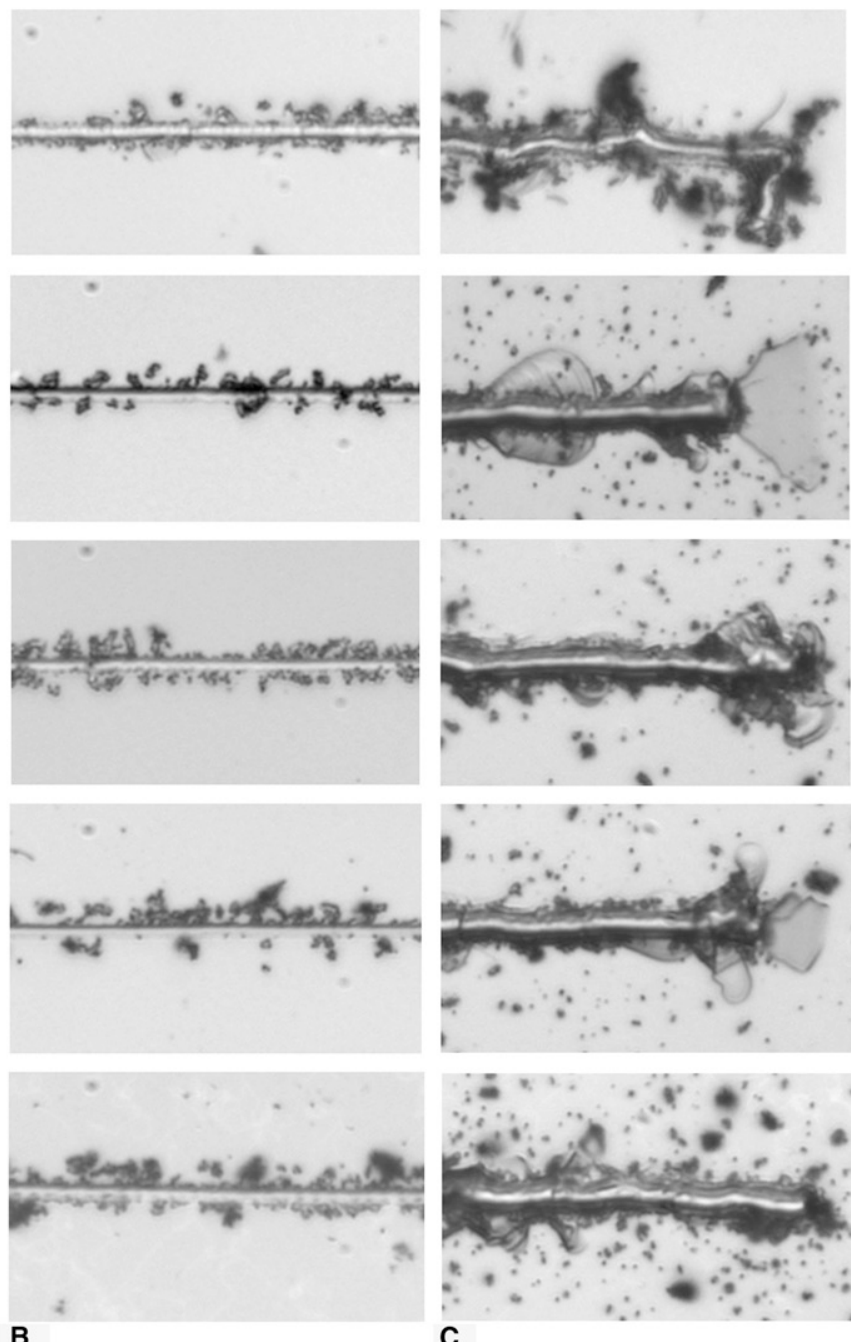

B
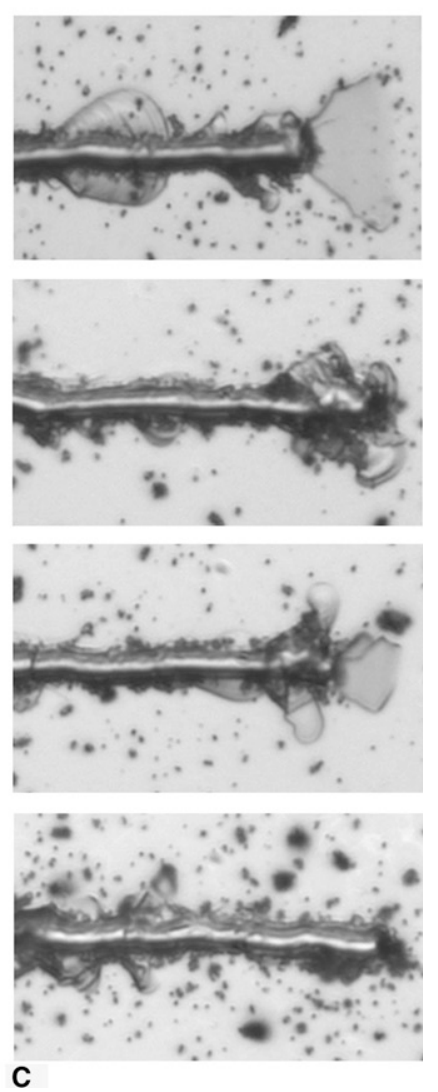

FIG. 6. Variation of AE signal and coefficient of friction as a function of normal load and optical images of three regions over scratches: at the beginning of the scratch (Column A), around the point of initiation of damage (Column B), and toward the end of the scratch (Column C) for all samples.

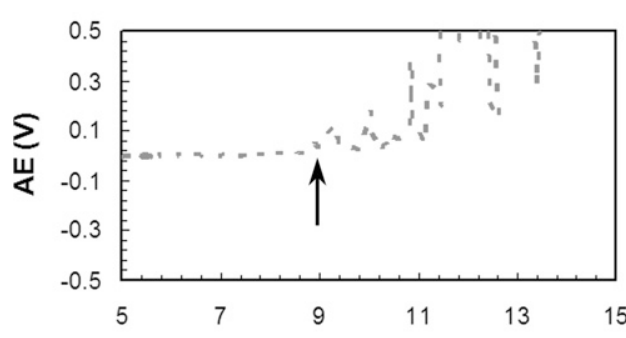

(a) (b)

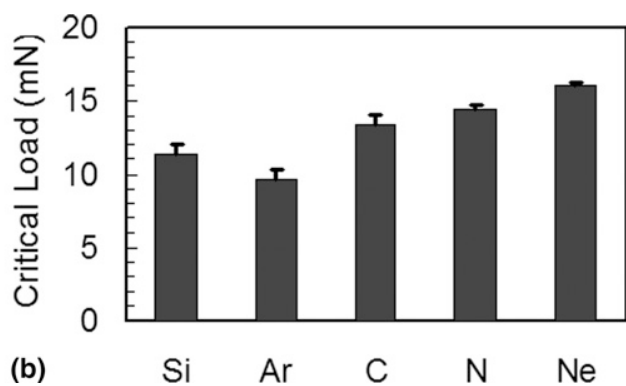

Si $\quad \operatorname{Ar} \quad \mathrm{C} \quad \mathrm{N} \quad \mathrm{Ne}$

FIG. 7. (a) A typical burst of AE signal. (b) Critical scratch loads for all samples. Error bars denote the standard errors.

by delamination of the ion implanted layers and fracture of both ion implanted layers and Si substrate.

\section{E. Friction and wear resistance}

The coefficient of friction as a function of sliding distance under constant wear forces of $0.05 \mathrm{~N}$ and $1.5 \mathrm{~N}$ for all samples is shown in Fig. 8. For the $0.05 \mathrm{~N}$ wear force, the coefficient of friction is almost constant for all samples except the $\mathrm{Ne}$ implanted one, for which the coefficient of friction slightly increases with increasing sliding distance. The values of the coefficient of friction are comparable at the beginning and the end 
$\mathrm{F}_{\mathrm{N}}$

$0.05 \mathrm{~N}$
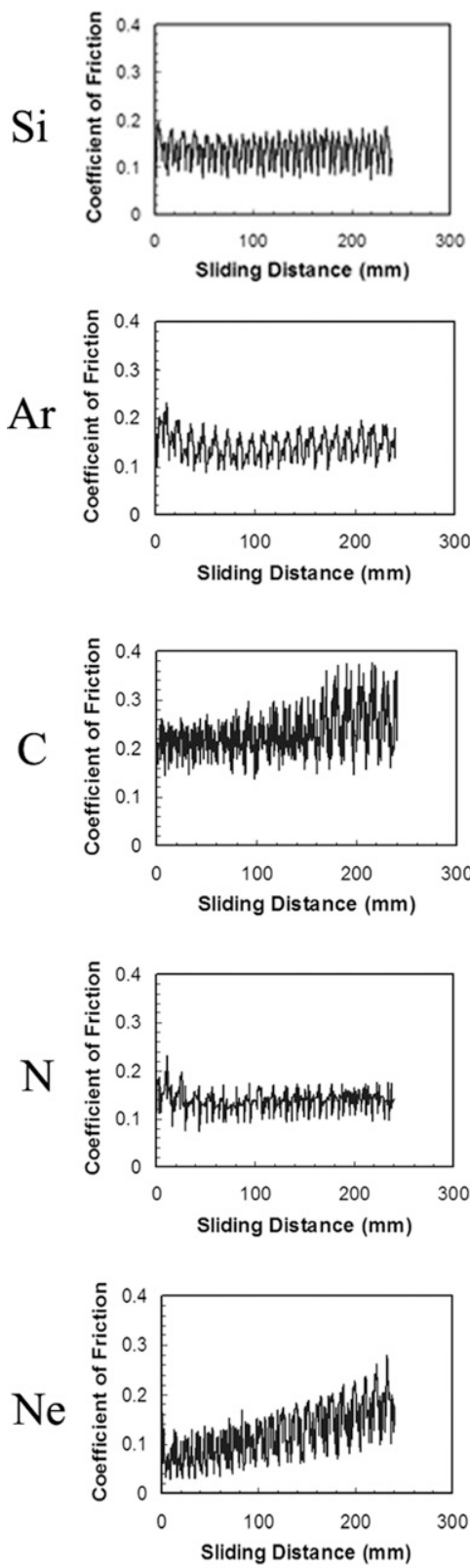

$1.5 \mathrm{~N}$
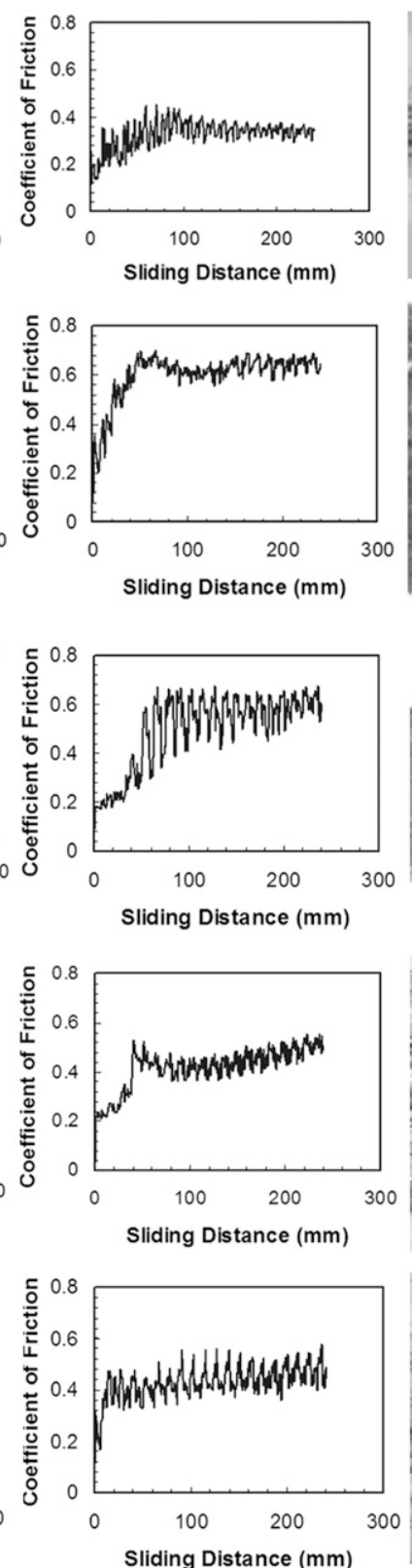

\section{$1.5 \mathrm{~N}$}
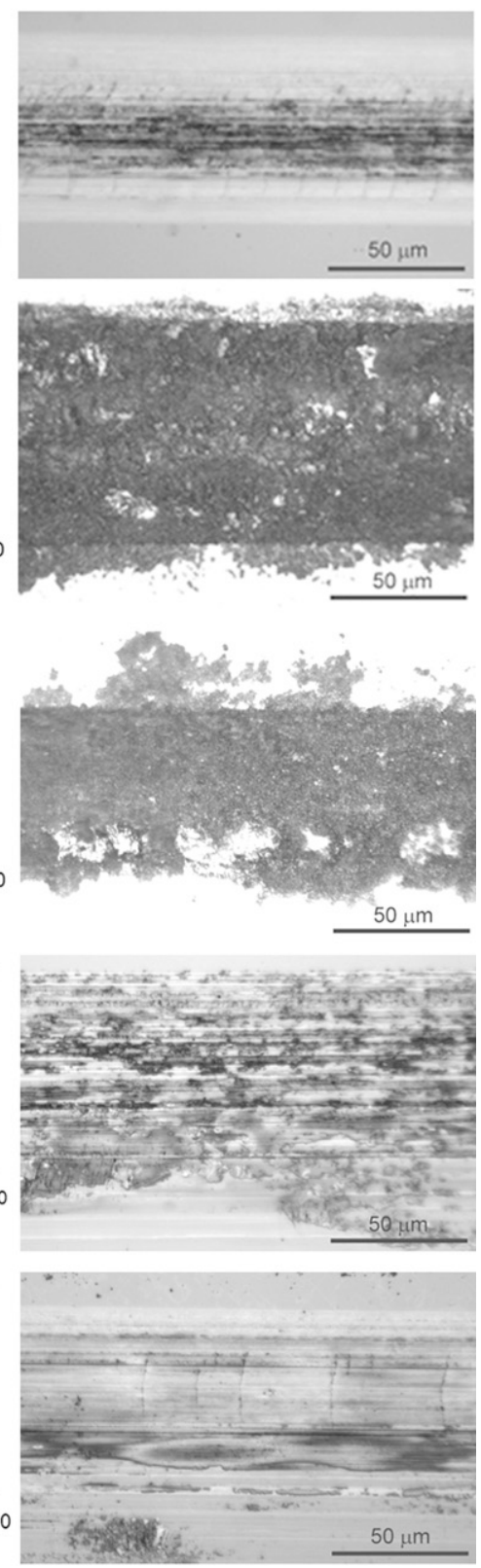

FIG. 8. Variation of coefficient of friction as a function of sliding distance under $0.05 \mathrm{~N}$ and $1.5 \mathrm{~N}$ normal wear forces $\left(F_{\mathrm{N}}\right)$ and optical images of wear tracks.

of wear with $0.05 \mathrm{~N}$ normal force for all samples as summarized in Table II. No wear tracks are observed for all samples after a sliding distance of $240 \mathrm{~mm}$ with $0.05 \mathrm{~N}$ wear force. For the $1.5 \mathrm{~N}$ wear force, the coefficient of friction for all samples increases steadily with the sliding distance at the beginning of the sliding due to plowing of the WC ball into materials at this stage. Then a sharp jump of coefficient of friction occurs, indicating the onset of severe damage of materials. With further increase of the sliding distance, the coefficient of friction is almost a constant or slightly increasing for all materials. This may be due to the formation of debris along the wear track serving as third body rolling in sliding, which reduces the coefficient of friction $^{40}$ and may compensate for the possible increase of coefficient of friction caused by further local damage. As expected, the coefficient of friction at the beginning of $1.5 \mathrm{~N}$ wear for all materials are similar to those of $0.05 \mathrm{~N}$ wear (see Table II). However, the coefficient of friction at the end of $1.5 \mathrm{~N}$ wear for all materials doubled or even tripled their values of the beginning of wear. Ar implanted sample has the highest 
coefficient of friction of 0.63 and the control sample has the smallest coefficient of friction of 0.24 leaving $\mathrm{C}(0.61), \mathrm{N}(0.52)$, and $\mathrm{Ne}(0.49)$ implanted samples in between. Optical images of wear tracks formed on all samples after a sliding distance of $240 \mathrm{~mm}$ with $1.5 \mathrm{~N}$ wear force are also shown in Fig. 8. Evidently, the Ar implanted sample has the most severe surface damage followed by $\mathrm{C}, \mathrm{N}$, and $\mathrm{Ne}$ implanted samples and the control sample.

\section{CONCLUSIONS}

$\mathrm{Ar}, \mathrm{C}, \mathrm{N}$, and Ne ions have been implanted in (100) single crystal silicon. AFM observation of all implanted surfaces shows a better surface roughness after ion implantation. Nanoindentation tests reveal a higher elastic modulus and hardness for all ion implantation except Ar compared to the control sample. It is found that all ion implantations except $\mathrm{Ne}$ enhance scratch resistance at the nanoscale. At the microscale, the ion implanted samples exhibit similar fracture toughness and scratch resistance to the control sample. A wear test at $0.05 \mathrm{~N}$ normal load reveals a comparable coefficient of friction among the ion implanted samples and the control samples, where no surface damage is observed. However, all ion implanted samples have higher coefficient of friction than the control samples for the wear test at $1.5 \mathrm{~N}$ normal load, where severe surface damage occurs.

\section{ACKNOWLEDGMENTS}

Financial support for this study was provided by the National Science Foundation (CMMI-0653651, CMMI0824728 and EPS-0296165) and the University of South Carolina NanoCenter.

\section{REFERENCES}

1. B. Bhushan and X.D. Li: Micromechanical and tribological characterization of doped single-crystal silicon and polysilicon films for microelectromechanical systems devices. J.Mater. Res. 12, 54 (1997).

2. B. Bhushan and B.K. Gupta: Handbook of Tribology: Materials, Coating, and Surface Treatments (McGraw-Hill, New York, 1991).

3. M. Szabadi, P. Hess, A.J. Kellock, H. Coufal, and J.E.E. Baglin: Elastic and mechanical properties of ion-implanted silicon determined by surface-acoustic-wave spectrometry. Phvs. Rev. B $\mathbf{5 8}$ 8941 (1998).

4. R. Sun, T. Xu, and Q.J. Xue: Effect of $\mathrm{Ar}^{+}$ion implantation on the nano-mechanical properties and microstructure of single crystal silicon. Appl. Surf. Sci. 249, 386 (2005).

5. P. Kodali, M. Hawley, K.C. Walter, K. Hubbard, N. Yu, J.R. Tesmer, T.E. Levine, and M. Nastasi: Tribological properties of carbon- and nitrogen-implanted Si (100). Wear 205, 144 (1997).

6. M. Ueda, C.M. Lepienski, E.C. Rangel, N.C. Cruz, and F.G. Dias: Nanohardness and contact angle of $\mathrm{Si}$ wafers implanted with $\mathrm{N}$ and $\mathrm{C}$ and $\mathrm{Al}$ alloy with $\mathrm{N}$ by plasma ion implantation. Surf. Coat. Technol. 156, 190 (2002).
7. P.K. Chu: Contamination issues in hydrogen plasma immersion ion implantation of silicon-A brief review. Surf. Coat. Technol. 156, 244 (2002).

8. S.V. Ovsyannikov, V.V. Shchennikov, I.V. Antonova, V.V. Shchennikov, Jr., and Y.S. Ponosov: Effect of hydrogen implantation on semiconductor-metal transition and high-pressure thermopower in Si. Mater. Sci. Eng., A 462, 343 (2007).

9. M. Ueda, A.F. Beloto, H. Reuther, and S. Parascandola: Plasma immersion ion implantation of nitrogen in $\mathrm{Si}$ : Formation of $\mathrm{SiO}_{2}$, $\mathrm{Si}_{3} \mathrm{~N}_{4}$ and stressed layers under thermal and sputtering effects. Surf. Coat. Technol. 136, 244 (2001).

10. J.G. Swadener and M. Nastasi: Increasing the fracture toughness of silicon by ion implantation. Nucl. Instrum. Methods Phys. Res., Sect. B 206, 937 (2003).

11. E. Oliviero, S. Peripolli, L. Amaral, P.F.P. Fichtner, M.F. Beaufort, J.F. Barbot, and S.E. Donnelly: Damage accumulation in neon implanted silicon. J. Appl. Phvs. 100, 043505 (2006).

12. P. Mishra, S.R. Bhattacharyya, and D. Ghose: Nanoindentation on single-crystal Si modified by $100 \mathrm{keV} \mathrm{Cr}+$ implantation. Nucl. Instrum. Methods Phys. Res., Sect. B 266, 1629 (2008).

13. P.M. Nagy, D. Aranyi, P. Horvath, G. Peto, and E. Kalman: Nanomechanical properties of ion-implanted Si. Surf. Interface Anal. 40,875 (2008).

14. Stopping and Range of Ions in Matter. http://www.srim.org/.

15. A. Simionescu, G. Hobler, S. Bogen, L. Frey, and H. Ryssel: Model for the electronic stopping power of channeled ions in silicon around the stopping power maximum. Nucl. Instrum. Methods Phys. Res., Sect. B 106, 47 (1995).

16. X. Chen and J. Vlassak: A numerical study on the measurements of thin film mechanical properties by means of nanoindentation. J. Mater. Res. 16, 2974 (2001).

17. Z.H. Xu and D. Rowcliffe: Finite element analysis of substrate effects on indentation behavior of thin films. Thin Solid Films 447-448, 399 (2004).

18. W.C. Oliver and G.M. Pharr: An improved technique for determining hardness and elastic modulus using load and displacement sensing indentation experiments. J. Mater. Res. 7, 1564 (1992).

19. Z.H. Xu and X.D. Li: Effects of indenter geometry and material properties on the correction factor of Sneddon's relationship for nanoindentation of elastic and elastic-plastic materials. Acta Mater. 56, 1399 (2008).

20. B.R. Lawn, A.G. Evans, and D.B. Marshall: Elastic/plastic indentation damage in ceramics: The median/radial crack system. J. Am. Ceram. Soc. 63, 574 (1980).

21. D.R. Franca and A. Blouin: All-optical measurement of in-plane and out-of-plane Young's modulus and Poisson's ratio in silicon wafers by means of vibration modes. Meas. Sci. Technol. 15, 859 (2004).

22. D.M. Follstaedt, J.A. Knapp, and S.M. Myers: Mechanical properties of ion-implanted amorphous silicon. J. Mater. Res. 19, 338 (2004).

23. P. Brault, P. Ranson, H. Estrade-Szwarckopf, and B. Rousseau: Chemical physics of fluorine plasma-etched silicon surfaces: Study of surface contaminations. J. Appl. Phvs. 68, 1702 (1990).

24. D. Rats, L. Vandenbulcke, R. Herbin, R. Benoit, R. Erre, V. Serin, and J. Sevely: Characterization of diamond films deposited on titanium and its alloys. Thin Solid Films 270, 177 (1995).

25. L.C. Chen, C.Y. Yang, D.M. Bhusari, K.H. Chen, M.C. Lin, and T.J. Chuang: Formation of crystalline silicon carbon nitride films by microwave plasma-enhanced chemical vapor deposition. Diamond Relat. Mater. 5, 514 (1996).

26. A.R. Chourasia: Core level XPS spectra of silicon carbide using zirconium and magnesium radiations. Surf. Sci. Spectra 8, 45 (2001).

27. L. Kubler, J.L. Bischoff, and D. Bolmont: General comparison of the surface processes involved in nitridation of $\mathrm{Si}(100)-2 \mathrm{X} 1$ by 
$\mathrm{NH}_{3}$ and in SiNx film deposition: A photoemission study. Phvs. Rev. B 38, 13113 (1988).

28. S. Adachi, H. Mori, and M. Takahashi: Model-dielectric-function analysis of ion-implanted Si (100) wafers. $\underline{\text { J. Appl. Phvs. 93, } 115}$ (2003).

29. D. Paramanik, S. Dey, V. Granesan, and S. Varma: Shape transition of nanostructures created on Si (100) surface after MeV implantation. Nucl. Instrum. Methods Phys. Res., Sect. B 244, 74 (2006).

30. H. Mori, S. Adachi, and M. Takahashi: Optical properties of selfion-implanted Si (100) studied by spectroscopic ellipsometry. J. Appl. Phvs. 90, 87 (2001).

31. G. Kuri and T.R. Yang: $\mathrm{MeV} \mathrm{Al}^{+}$and $\mathrm{Al}_{2}{ }^{+}$ions implantation in Si (100): Surface roughness and defects in the bulk. Appl. Phvs. A 79, 443 (2000).

32. K. Tsunoda, S. Adachi, and M. Takahashi: Spectroscopic ellipsometry study of ion-implanted Si (100) wafers. J. Appl. Phvs. 91 2936 (2002).

33. A. Leyland and A. Matthews: On the significance of the $H / E$ ratio in wear control: A nanocomposite coating approach to optimized tribological behaviour. Wear 240.1 (2000).
34. B. Shi, J.L. Sullivan, and B.D. Beake: An investigation into which factors control the nanotribological behaviour of thin sputtered carbon films. J. Phvs. D: Appl. Phvs. 41, 045303 (2008).

35. X.D. Li, B. Bhushan, K. Takashima, C.W. Baek, and Y.K. Kim: Mechanical characterization of micro/nanoscale structures for MEMS/NEMS applications using nanoindentation techniques. Ultramicroscopv 97, 481 (2003).

36. X.D. Li and B. Bhushan: Micro/nanomechanical and tribological studies of bulk and thin-film materials used in magnetic recording heads. Thin Solid Films 398-399, 313 (2001).

37. H. Jensen, U.M. Jensen, and G. Sorensen: Reactively sputtered Cr nitride coatings studies using the acoustic emission scratch test technique. Surf. Coat. Technol. 74-75, 297 (1995).

38. S.S. Cho and K. Komvopoulos: Correlation between acoustic emission and wear of multi-layer ceramic coated carbide tools. Trans. ASME 119, 238 (1997).

39. C.W. Cho and Y.Z. Lee: Wear-life evaluation of CrN-coated steels using acoustic emission signals. Surf. Coat. Technol. 127,59 (2000).

40. T.E. Fischer, Z. Zhu, H. Kim, and D.S. Shin: Genesis and role of wear debris in sliding wear of ceramics. Wear 245, 53 (2000). 